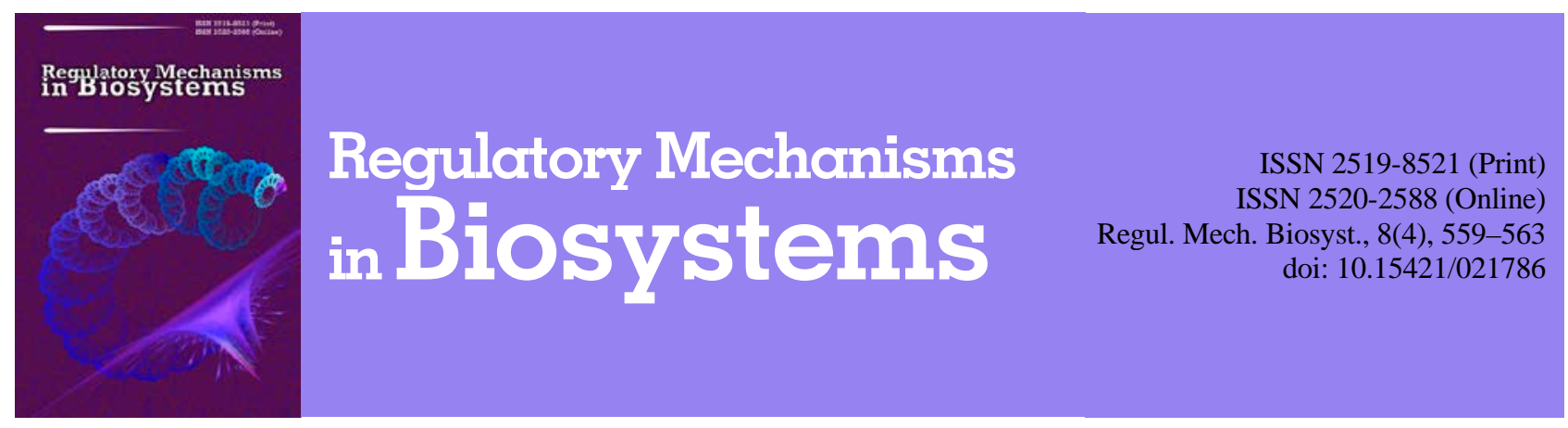

\title{
Characteristics of antibiotic sensitivity of Staphylococcus aureus isolated from dairy farms in Ukraine
}

\author{
O. M. Berhilevych*, V. V. Kasianchuk*, M. D. Kukhtyn**, \\ I. M. Lotskin***, T. O. Garkavenko****, P. A. Shubin* \\ *Sumy State University, Sumy, Ukraine \\ **Ternopil Ivan Puluj National Technical University, Ternopil, Ukraine \\ ***Sumy National Agrarian University, Sumy, Ukraine \\ ****State Scientific and Research Institute of Laboratory Diagnostics and Veterinary and Sanitary Expertise, Kyiv, Ukraine
}

Article info

$$
\begin{gathered}
\text { Received 28.09.2017 } \\
\text { Received in revised form } \\
\text { 07.11.2017 } \\
\text { Accepted 12.11.2017 }
\end{gathered}
$$

Sumy State University, Sanatorna st., 31,

Sumy, 40018, Ukraine.

Tel.: +38-067-903-89-96

E-mail:

o.bergylevych@med.sumdu.edu.ua

Ternopil Ivan Puluj National

Technical University, Rus'ka st.,

56, Ternopil, 46001, Ukraine.

Sumy National Agrarian

University, Gerasym Kondrat'ev

st., 160, Sumy, 40000, Ukraine.

State Scientific and Research Institute of Laboratory

Diagnostics and Veterinary and Sanitary Expertise, Donetska st., 30, Kyiv, 03151, Ukraine.

\begin{abstract}
Berhilevych, O. M., Kasianchuk, V. V., Kukhtyn, M. D., Lotskin, I. M., Garkavenko, T. O., \& Shubin, P. A. (2017). Characteristics of antibiotic sensitivity of Staphylococcus aureus isolated from dairy farms in Ukraine. Regulatory Mechanisms in Biosystems, 8(4), 559-563. doi:10.15421/021786
\end{abstract}

Staphylococcus aureus is one of the most important microorganism in the process of raw milk production and has significance for people's health as it causes dangerous microbial contamination of dairy production. Furthermore, raw milk and the environment of livestock farms may be potential vehicles for distribution of antibiotic-resistant strains of S. aureus. The aim of the present study was to establish antibiotic sensitivity profiles of S. aureus depending on its origin from dairy farms, with a special focus on methicillin-resistant isolates. A total of 165 samples were collected for investigation in the period 2014-2016 from 5 dairy farms in Ukraine. All samples were analyzed for the presence of $S$. aureus using the Baird Parker Agar with Egg Yolk Tellurite Emulsion. Typical staphylococcal colonies were examined morphologically and for presence of coagulase and hemolysin activities. From these, positive samples for $S$. aureus were 62 (37.6\%): 4 (6.5\%) raw milk, 17 (77.4\%) swabs of udder skin, 18 (29.0\%) milk from cows with subclinical mastitis and 21 (33.9\%) environmental samples. The standard disk diffusion method was used to determine sensitivity of $S$. aureus isolates to 10 antibiotics. The antimicrobial sensitivity profiles of $S$. aureus isolates showed differences between them, which depends on the origin of the isolates. Our results demonstrated that most of $S$. aureus isolates were resistant to penicillin, oxacillin and vancomycin. Of the 62 S.aureus isolates, 20 (32.3\%) and 5 (8.1\%) were found to be multiresistant to 3 different antibiotics, 6 (9.8\%) isolates to 4 antibiotics, $12(19.4 \%)$ and 3 (4.8\%) to 5 antibiotics $\left(\mathrm{P}^{10}, \mathrm{OX}^{1}, \mathrm{VA}^{5}, \mathrm{~L}^{10}, \mathrm{TE}^{30}\right.$ and $\mathrm{P}^{10}, \mathrm{OX}^{1}, \mathrm{VA}^{5}, \mathrm{CIP}^{10}, \mathrm{TE}^{30}$ respectively). All isolates resistant to penicillin and oxacillin were typed by mec A gene in PCR with two primers (MecA147-F and MecA147-R). The results show that $66.7 \%$ of these isolates yielded a mecA product. The information obtained from this study is useful for understanding the prevalence of $S$. aureus and its antibiotic sensitivity in dairy farms and can be useful for local and national monitoring or for designing specific control programs of methicillin- and multiresistance isolates present in the food chain of milk production.

Keywords: raw milk; objects of dairy farms; antibiotic sensitivity profiles; MRSA; mecA gene

\section{Introduction}

Staphylococcus aureus is an opportunistic pathogen of human or animal skin and mucosal surfaces. It is well known that this microorganism can cause a wide range of infections such as skin infection (abscesses, carbuncle, furuncle and impetigo), pneumonia, osteomyelitis, endocarditis, sepsis and toxic shock syndrome. Also, it is common knowledge that $S$. aureus can be an agente responsible for food poisoning in people with severe vomiting and diarrhea. Most often poisoning is caused by the enterotoxins of S. aureus that are accumulated in milk or dairy products as result of multiplication of this type of microorganism (Bhunia, 2008; Wang et al., 2014; Brennan et al., 2016).

Therefore $S$. aureus has become an important problem in raw milk production and the dairy industry all over the world ( $\mathrm{Li}$ et al., 2009; Ateba et al., 2010; Szweda et al., 2014; Carfora et al., 2015). There are many ways in which staphylococci enter raw milk and dairy products during their production. First of all, S. aureus can live on the surface of the skin of cow udders or even in the teat canals and, under certain conditions, causes subclinical and clinical mastitis in dairy cows. In this case, infected mammary glands are the main reservoir of contamination of raw cows' milk, dairy equipment and the dairy farm environment by these microorganisms (Febler et al., 2010; Basanisi et al., 2017; Hamid et al., 2017). Secondly, S. aureus can survive and persist in these objects for a long time and contaminate raw milk again. Few researchers have published information about biofilm formation by $S$. aureus on dairy equipment, from which bacteria penetrate raw milk, reducing the time of its shelf life and also cause poisoning of consumers (Kirmusaoglu, 2017; Kukhtyn et al., 2017).

But, the big problem of $S$. aureus in milk production is aggravated by the fact that the microorganism can quickly adapt to environmental conditions including antibiotics, which are used in livestock for treatment or as additives for animal feed. The long-term use of antibiotics on dairy farms has increased $S$. aureus resistance to antibiotics and particular to $\beta$-lactams (MRSA - methicillin-resistant S. aureus) (Keefe, 2012; Al-Ashmawy et al., 2016; Doulgeraki et al., 2017). The methicillin resistance characteristic in $S$. aureus is due to the presence of altered 
penicillin binding protein (PBP2a) in the cell wall that has a reduced binding affinity to $\beta$-lactam antibiotics. PBP2a is encoded by mecA gene that is located in the large chromosomal cassette called staphylococcal chromosome cassette mec element (SCCmec) (Zhang and McClure, 2005; Ganai et al., 2016; Rahim et al., 2017).

Epidemiologically MRSA which were isolated from livestock animals, from workers in animal farms or the food production chain equipment and from the products of animal origin indicate as LA-MRSA (livestock-associated MRSA). In recent years, many studies have been published on the isolation and distribution of antibiotic resistance among S. aureus isolates from different sources of dairy farms depending on the geographical localization where each investigation was conducted. According to this data, wide variation in MRSA prevalence has been observed (Pu et al., 2014; Mehli et al., 2017; Sergelidis and Angelidis, 2017).

Moreover, MRSA has the ability to resist different antibiotics and become a multidrug-resistant microorganism (Thaker et al., 2013; Ateba et al., 2016). Thus, this pathogen has become a major concern in the livestock industry as well as a public health hazard (Jihasz-Kaszanytzky et al., 2007; Sergelidis and Angelidis, 2017).

However, there has been little discussion in the literature about antibiotic sensitivity of $S$. aureus isolated from raw milk and dairy farms environments in Ukraine. Against this background, the present paper aims to identify the prevalence of $S$. aureus on dairy farm facilities and milk samples from raw cows, to establish their antimicrobial sensitivity profiles with a special focus on methicillin-resistant isolates. The following tasks were pursued in this study: (i) isolation of S. aureus from samples (ii) study of their antimicrobial sensitivity depending on their origin (iii) typing methicillin-resistant isolates by mec A gene in PCR.

\section{Materials and methods}

Samples collection. A total of 165 samples: 32 samples of raw milk, 38 swabs of udder skin, 38 samples of milk from cows with subclinical mastitis and 57 environmental samples (10 swabs of milking machines, 13 swabs of milk tanks, 10 samples of animal feed, 24 swabs from floors of farm buildings) were collected for investigation in the period from 2014 till 2016 from 5 dairy farms in Sumy Region, Ukraine. The herd structure was characterized by medium-holder stateowned dairy farms with lactating cows from 1,500 to 1,000 per herd. All farms had similar breeding and milking systems. The cows were milked twice a day using milking machine.

The raw milk samples to the amount of $250 \mathrm{ml}$ were taken in sterile bottles directly from milk tanks. The milk from cows with subclinical mastitis was collected after indicating it by using the Rapid California Mastitis Test (CMT, DeLaval). Swabs from the surface of udder skin of cows and swabs from milking machines, milk tanks and from floors were taken using cotton-tipped swabs. All samples were transported to the laboratory in containers with ice and then were immediately analyzed within 24 hours.

Methods of isolation and identification $S$. aureus from samples. For detection of staphylococci, all samples were inoculated onto BairdParker Agar with Egg Yolk Tellurite Emulsion (Himedia, India) and cultivated at $35-37^{\circ} \mathrm{C}$ for $24-48 \mathrm{~h}$ aerobically. Typical staphylococcal colonies (black, convex, shiny colonies surrounded by clear zones) were used for microscopic examination, and the coagulase test with rabbit plasma and for production of hemolysin on Blood Agar to distinguish
S. aureus from other staphylococci. On microscopic examination, all the $S$. aureus isolates were found to be Gram positive, non-spore forming, nonmotile cocci, giving a clustered bunch of grape (Bhunia, 2008).

Antimicrobial susceptibility testing. Ten antimicrobial agents (Oxoid, UK): penicillin (10 IU/disk), oxacillin (1 $\mu \mathrm{g} /$ disk), gentamicin (10 $\mu \mathrm{g} /$ disk $)$, streptomycin $(10 \mu \mathrm{g} /$ disk $)$, vancomycin (5 $\mu \mathrm{g} /$ disk $)$, enrofloxacin $(10 \mu \mathrm{g} /$ disk), ciprofloxacin (10 $\mu \mathrm{g} /$ disk), lincomycin $(10 \mu \mathrm{g})$, erythromycin $(15 \mathrm{mkg} /$ disk), tetracycline $(30 \mu \mathrm{g} /$ disk) were tested in this study. Antibiotic sensitivity of S. aureus isolates was tested by the standard disk diffusion method on Mueller - Hinton Agar (Oxoid, UK) according to the guide. Based on the inhibition zone size, results were recorded as "Susceptible," "Intermediate," or "Resistant" according to the interpretive criteria specified in CLSI (Performance Standards for Antimicrobial Disk Susceptibility Tests, 2012).

mec A PCR typing. The mecA PCR typing was carried out with two primers according to technique described by Zhang and McClure (2005). MecA147-F (GTG AAG ATA TAC CAA GTG ATT) and MecA147-R (ATG CGC TAT AGA TTG AAA GGA T) were used for it. In brief, DNA isolation of $S$. aureus was performed by the following steps: a colony of pure culture was suspended in a test tube with $0.5 \mathrm{~cm}^{3}$ of sterile deionized water, then was heated for 10 minutes at $99^{\circ} \mathrm{C}$, after centrifugation at $30,000 \mathrm{~g}$ for $1 \mathrm{~min}, 2 \mu \mathrm{l}$ of the supernatant was used as template in a $25 \mu \mathrm{l}$ PCR. Polymerase chain reaction was performed in termocycles "Tertsyk" (DNA technology, Russia) and "T1" (Biometra, Germany). Thermal cycling parameters were as follows: $95^{\circ} \mathrm{C}$ for $4 \mathrm{~min}$ (1 cycle), followed by 35 cycles of $95^{\circ} \mathrm{C}$ for $30 \mathrm{~s}, 50^{\circ} \mathrm{C}$ for $30 \mathrm{~s}, 72{ }^{\circ} \mathrm{C}$ for $30 \mathrm{~s}$; and a terminal extension step of $72{ }^{\circ} \mathrm{C}$ for $7 \mathrm{~min}$.

\section{Results}

Isolation of $\boldsymbol{S}$. aureus from samples. A total of 62 (37.6\%) S. aureus isolates from 165 investigated samples were detected. As can be seen in Table 1, the highest percentage of samples, from which S. aureus was isolated, were from farm 4 (58.1\% positive samples) and from farm 2 (51.5\% positive samples). And conversely, the smallest number of positive samples was determined from farms 3 and 5 (21.6\% and $29.0 \%$ respectively). The results also show that $S$. aureus was isolated from 2.4\% (4/165) samples of raw milk, from 10.3\% (17/165) of samples of swabs from the surface of udder skin and from $10.9 \%$ (18/165) of samples of milk from cows with subclinical mastitis. A total of 57 environmental samples were examined and 21 were positive (12.7\% from all investigated samples).

Antibiotic susceptibility testing of $S$. aureus isolates. Antibiotic susceptibility testing of $62 \mathrm{~S}$. aureus isolates from 5 farms was done by the disk diffusion method on Mueller - Hinton Agar using disks of 10 antibiotics. The results of the testing of all S. aureus isolates are shown in Table 2. It has been found that the level of antimicrobial sensitivity of the investigated $S$. aureus isolates was different in each farm. But, interestingly, that a significaly higher number of resistant $S$. aureus isolates were detected from farm 2 . Twelve $S$. aureus isolates from 17 investigated $(82.4 \%)$ were resistant to $5\left(\mathrm{P}^{10}, \mathrm{OX}^{1}, \mathrm{VA}^{5}, \mathrm{~L}^{10}, \mathrm{TE}^{30}\right)$ of 10 tested antibiotics. Interestingly, that the same situation was found with isolates from farm 4, but relating to resistance to other antibiotics $\left(\mathrm{P}^{10}, \mathrm{OX}^{1}\right.$, $\mathrm{VA}^{5}, \mathrm{CIP}^{10}, \mathrm{TE}^{30}$ ). And conversely, a low number of samples with resistant $S$. aureus were found from farms 1 and 3. Isolates showed resistance to $2-3$ antibiotics.

Table 1

Results of S. aureus isolates detection from samples $(n=165)$

\begin{tabular}{|c|c|c|c|c|c|c|c|c|c|c|c|c|c|c|c|}
\hline \multirow{2}{*}{ Samples } & \multicolumn{3}{|c|}{ Farm 1} & \multicolumn{3}{|c|}{ Farm 2} & \multicolumn{3}{|c|}{ Farm 3} & \multicolumn{3}{|c|}{ Farm 4} & \multicolumn{3}{|c|}{ Farm 5} \\
\hline & $\mathrm{N}$ & $\mathrm{n}$ & $\%$ & $\mathrm{~N}$ & $\mathrm{n}$ & $\%$ & $\mathrm{~N}$ & $\mathrm{n}$ & $\%$ & $\mathrm{~N}$ & $\mathrm{n}$ & $\%$ & $\mathrm{~N}$ & $\mathrm{n}$ & $\%$ \\
\hline Raw milk & 5 & 0 & 0.0 & 7 & 2 & 28.6 & 5 & 0 & 0.0 & 8 & 2 & 25.0 & 7 & 0 & 0.0 \\
\hline Swabs of udder skin & 8 & 3 & 37.5 & 8 & 4 & 37.5 & 10 & 2 & 20.0 & 5 & 4 & 80.0 & 7 & 4 & 57.1 \\
\hline Milk from cows with subclinical mastitis & 8 & 3 & 37.5 & 8 & 5 & 62.5 & 10 & 3 & 30.0 & 7 & 5 & 71.4 & 5 & 2 & 40.0 \\
\hline Environmental samples & 12 & 4 & 33.3 & 10 & 6 & 60.0 & 12 & 3 & 25.0 & 11 & 5 & 45.6 & 12 & 3 & 25.0 \\
\hline Total & 33 & 10 & 30.3 & 33 & 17 & 51.5 & 37 & 8 & 21.6 & 31 & 18 & 58.1 & 31 & 9 & 29.0 \\
\hline
\end{tabular}

Note: $\mathrm{N}$ - number of investigated samples, $\mathrm{n}$ - number of positive samples, \% - percentages of positive samples. 
Table 2

Antibiotic sensitivity of $S$. aureus isolates from dairy farms $(\mathrm{n}=62)$

\begin{tabular}{|c|c|c|c|c|c|c|c|c|c|c|c|c|c|c|c|}
\hline \multirow{3}{*}{ Antibiotics } & \multicolumn{15}{|c|}{ No. (\%) of S. aureus isolates from } \\
\hline & \multicolumn{3}{|c|}{ Farm $1(n=10)$} & \multicolumn{3}{|c|}{ Farm $2(\mathrm{n}=17)$} & \multicolumn{3}{|c|}{ Farm $3(\mathrm{n}=8)$} & \multicolumn{3}{|c|}{ Farm $4(\mathrm{n}=18)$} & \multicolumn{3}{|c|}{ Farm 5 $(\mathrm{n}=9)$} \\
\hline & $\mathrm{S}$ & I & $\mathrm{R}$ & $\mathrm{S}$ & I & $\mathrm{R}$ & $\mathrm{S}$ & I & $\mathrm{R}$ & $\mathrm{S}$ & I & $\mathrm{R}$ & $\mathrm{S}$ & I & $\mathrm{R}$ \\
\hline$\overline{\mathrm{P}^{10}}$ & 0 & $2(20.0)$ & $8(80.0)$ & 0 & 0 & $17(100.0)$ & 0 & 0 & $8(100.0)$ & $2(11.2)$ & $8(44.4)$ & $8(44.4)$ & 0 & 0 & $9(100.0)$ \\
\hline $\mathrm{OX}^{1}$ & $3(30.0)$ & $1(10.0)$ & $6(60.0)$ & 0 & $5(29.4)$ & $12(70.6)$ & 0 & $2(25.0)$ & $6(75.0)$ & $12(66.6)$ & $3(16.7)$ & $3(16.7)$ & $3(33.3)$ & 0 & 6(66.7) \\
\hline GEN $^{10}$ & $10(100.0)$ & 0 & 0 & $12(70.6)$ & $3(17.6)$ & $2(11.8)$ & $8(100.0)$ & 0 & 0 & $18(100.0)$ & 0 & 0 & $9(100.0)$ & 0 & 0 \\
\hline$S^{10}$ & $7(70.0)$ & $2(20.0)$ & 0 & $11(64.8)$ & $3(17.6)$ & $3(17.6)$ & $8(100.0)$ & 0 & 0 & $15(83.3)$ & $3(16.7)$ & 0 & $6(66.7)$ & $3(33.3)$ & 0 \\
\hline $\mathrm{VA}^{5}$ & $4(40.0)$ & $1(10.0)$ & $5(50.0)$ & $2(11.8)$ & $3(17.6)$ & $12(70.6)$ & $5(62.5)$ & $3(37.5)$ & 0 & $15(83.3)$ & 0 & $3(16.7)$ & $9(100.0)$ & 0 & 0 \\
\hline $\mathrm{EX}^{10}$ & $8(80.0)$ & $2(20.0)$ & 0 & $13(76.6)$ & $2(11.8)$ & $2(11.8)$ & $8(100.0)$ & 0 & 0 & $18(100.0)$ & 0 & 0 & $9(100.0)$ & 0 & 0 \\
\hline $\mathrm{CIP}^{10}$ & & $1(10.0)$ & 0 & & $3(17.6)$ & $2(11.8)$ & $9(87.5)$ & $1(12.5)$ & 0 & 56.6) & $3(16.7)$ & $3(16.7)$ & $6(66.7)$ & $3(33.3)$ & 0 \\
\hline $\mathrm{L}^{10}$ & $8(80.0)$ & $2(20.0)$ & 0 & $3(17.6)$ & $2(11.8)$ & $12(70.6)$ & $5(62.5)$ & $3(37.5)$ & 0 & $15(83.3)$ & $3(16.7)$ & 0 & $5(55.6)$ & 0 & $4(44.4)$ \\
\hline$E^{15}$ & $10(100.0)$ & 0 & 0 & $5(29.6)$ & $12(70.6)$ & 0 & $5(62.5)$ & $3(37.5)$ & 0 & $14(77.8)$ & $4(22.2)$ & 0 & 7 (77.8) & & $2(22.2)$ \\
\hline $\mathrm{TE}^{30}$ & $6(60.0)$ & $4(40.0)$ & 0 & $2(11.8)$ & $3(17.6)$ & $12(70.6)$ & $5(62.5)$ & $3(37.5)$ & 0 & 10 (55.6) & $2(11.1)$ & $6(33.3)$ & $9(100.0)$ & 0 & 0 \\
\hline
\end{tabular}

Note: $\mathrm{P}^{10}$ - penicillin (10 IU/disk), OX ${ }^{1}$ - oxacillin $(1 \mu \mathrm{g} /$ disk $)$, GEN ${ }^{10}-$ gentamicin $(10 \mu \mathrm{g} /$ disk $), \mathrm{S}^{10}-$ streptomycin $(10 \mu \mathrm{g} /$ disk $), \mathrm{VA}^{5}-\mathrm{vancomycin}$ $(5 \mu \mathrm{g} / \mathrm{disk}), \mathrm{EX}^{10}-$ enrofloxacin $(10 \mu \mathrm{g} /$ disk $), \mathrm{CIP}^{10}$ - ciprofloxacin $(10 \mu \mathrm{g} /$ disk $), \mathrm{L}^{10}-$ lincomycin $(10 \mu \mathrm{g}), \mathrm{E}^{15}$ - erythromycin $(15 \mathrm{mkg} / \mathrm{disk}), \mathrm{TE}^{30}-$ tetracycline (30 $\mu \mathrm{g} /$ disk); interpretive criteria for antimicrobial sensitivity of S. aureus isolates: S - susceptible, I - intermediate, R - resistant.

The highest percentage of resistance among investigated isolates was observed in the case of $\beta$-lactam antibiotics: penicillin $(n=50$, 80.6\%) and oxacillin ( $\mathrm{n}=33,53.2 \%)$. Despite this, 20 isolates (32.3\%) that were resistant to penicillin and oxacillin were also resistant to vancomycin. It has been found that, the high resistance was also observed in the case of lincomycin $(n=16,25.8 \%)$ and tetracycline $(n=18$, $29.0 \%$ ). The rates of resistance to ciprofloxacin and streptomycin were 9.9\% (6/62) and 4.8\% (3/62), respectively. Gentamicin, enrofloxacin and erythromycin were active against most of tested isolates.

Antimicrobial resistance varied among $S$. aureus isolates, isolated from the different sources. The antimicrobial resistance of $S$. aureus isolates from swabs of udder skin from cows and samples of milk from cows with subclinical mastitis were higher in comparison to other samples. A significant difference in antimicrobial resistance was observed between the abovementioned isolates and isolates obtained from environmental samples.

Table 3 demonstrates antibiotic resistance profiles of isolates. Of the 62 S. aureus isolates, 20 (32.3\%) and 5 (8.1\%) were found as multiresistant to 3 antibiotics. Also, the analysis indicates that $6(9.8 \%)$ isolates were resistant to 4 antibiotics. As mentioned above, $12 \mathrm{~S}$. aureus isolates were resistant to 5 antibiotics $\left(\mathrm{P}^{10}, \mathrm{OX}^{1}, \mathrm{VA}^{5}, \mathrm{~L}^{10}, \mathrm{TE}^{30}\right)$ and

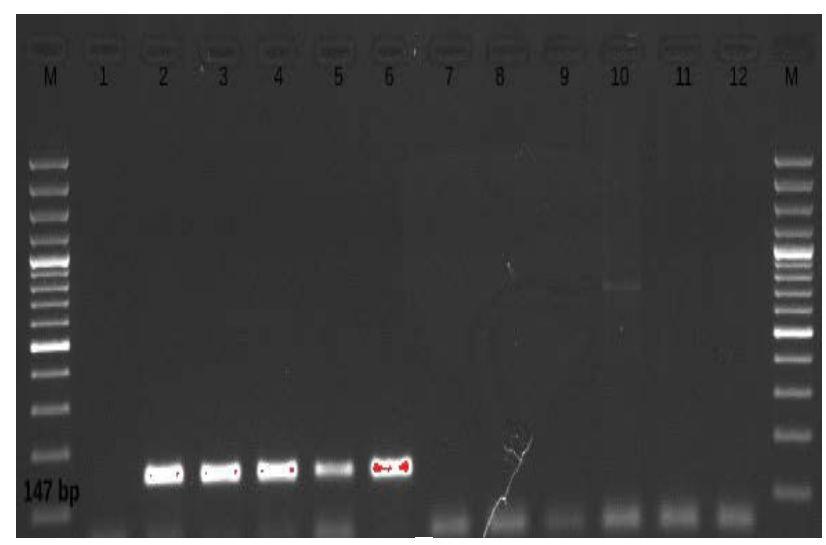

the 3 isolates were resistant to another 5 antibiotics $\left(\mathrm{P}^{10}, \mathrm{OX}^{1}, \mathrm{VA}^{5}\right.$, $\left.\mathrm{CIP}^{10}, \mathrm{TE}^{30}\right)$.

Table 3

The antibiotic resistance profiles of $S$. aureus isolates $(\mathrm{n}=62)$

\begin{tabular}{lcc}
\hline \multicolumn{1}{c}{ Combination of antibiotic } & $\begin{array}{c}\text { Number } \\
\text { of isolates }\end{array}$ & $\begin{array}{c}\text { Percentage } \\
\text { of isolates, } \%\end{array}$ \\
\hline $\mathrm{P}^{10}, \mathrm{OX}^{1}$ & 33 & 53.2 \\
$\mathrm{P}^{10}, \mathrm{OX}^{1}, \mathrm{VA}^{5}$ & 20 & 32.3 \\
$\mathrm{P}^{10}, \mathrm{OX}^{1}, \mathrm{~L}^{10}$ & 5 & 8.1 \\
$\mathrm{P}^{10}, \mathrm{OX}^{1}, \mathrm{TE}^{30}$ & 6 & 9.8 \\
$\mathrm{P}^{10}, \mathrm{OX}^{1}, \mathrm{VA}^{5}, \mathrm{TE}^{30}$ & 6 & 9.8 \\
$\mathrm{P}^{10}, \mathrm{OX}^{1}, \mathrm{~L}^{10}, \mathrm{TE}^{30}$ & 7 & 11.3 \\
$\mathrm{P}^{10}, \mathrm{OX}^{1}, \mathrm{VA}^{5}, \mathrm{~L}^{10}, \mathrm{TE}^{30}$ & 12 & 19.4 \\
$\mathrm{P}^{10}, \mathrm{OX}^{1}, \mathrm{VA}^{5}, \mathrm{CIP}^{10}, \mathrm{TE}^{30}$ & 3 & 4.8 \\
\hline
\end{tabular}

PCR typing. Initially, 15 isolates ( 3 from raw milk, 3 from swabs of udder skin and 9 from environmental samples) were identified as suspected isolates with typical cultural and antibiotic resistance (to $\beta$-lactams) properties. Conclusive statement concerning methicillin-resistant isolates was performed by detection of mecA gene in isolates by PCR method (Fig. 1).

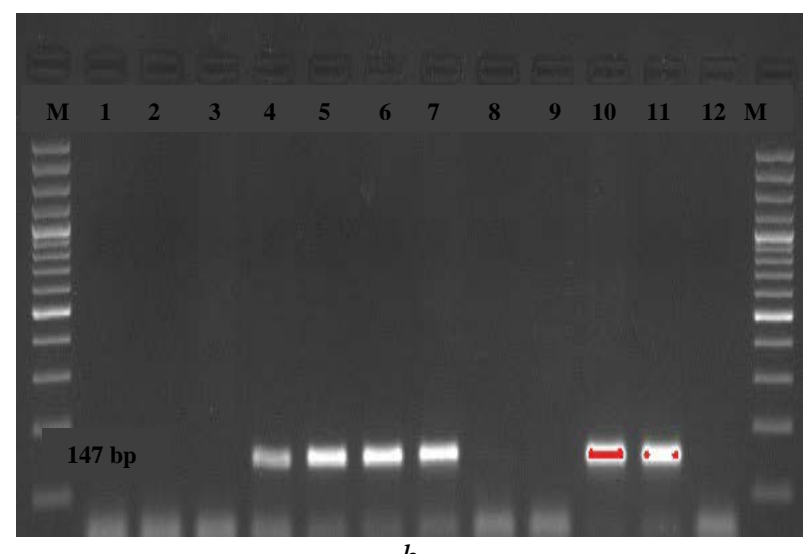

b

Fig. 1. PCR amplification of the mecA gene in selected S. aureus isolates: $a$ : $\mathrm{M}-100$ bp molecular weight marker, 1 - negative control, 2 - positive control, 3-6 - amplified product of 147 bp of mecA gene, 7-12 - no amplified products of mecA gene; $b$ : M - 100 bp molecular weight marker, 4-7, 10, 11 - amplified product of $147 \mathrm{bp}$ of mecA gene, 1-3, 8, 9, 12 - no amplified products of mecA gene

The results show that 10 (66.7\%) from 15 isolates of $S$. aureus yielded a mecA product.

\section{Discussion}

In the last few decades the number of publications about antibiotic resistance of microorganisms has increased and it is one of the most serious problem for human and animal health in the world (Normanno et al., 2007; Li et al., 2009; Gopal and Divya, 2017). In this paper we study antimicrobial sensitivity profiles of Staphylococcus aureus from 5 dairy farms in Ukraine with a special focus on methicillin-resistant isolates. Despite the fact that similar studies have been conducted by other authors in different regions of the world (İkiz et al., 2013; Szweda et al., 2014; Abebe et al., 2016), this is the first study in Ukraine concerning antimicrobial sensitivity profiles of $S$. aureus isolates from dairy farms, genetic typing of methicillin-resistant isolates by mec A gene in PCR and identifying of multiresistance.

We started our investigation with isolation of S. aureus from 165 collected samples. S. aureus isolates were detected in $37.6 \%$ of these. But we indicated 2 farms with the highest percentage (58.1\% and 
$51.5 \%$ ) of samples from which S. aureus was isolated and 1 farm with the smallest number of positive samples (21.6\%). Our results also show that the higher prevalence of $S$. aureus was found from environmental samples (12.7\%) and the lowest in raw milk (2.4\%). Other studies report different rates of raw milk contamination with $S$. aureus: $35.0 \%$ in Egypt (Al-Ashmawy et al., 2016), 17.9-35.4\% in South Africa (Ateba et al., 2010), 12.9\% in South Italy (Basanisi et al., 2017). But other potential sources of contamination of raw milk with $S$. aureus also can be the surface of udder skin (10.3\% positive samples) and milk from cows with subclinical mastitis (10.9\% positive samples). These results can be found in other studies (İkiz et al., 2013; Bardiau et al., 2013; Pu et al., 2014; Szweda et al., 2014).

But, the main task of this study was to characterize of antibiotic sensitivity of $S$. aureus isolates. In this study, 10 antibiotics for testing were selected based on 3 main factors: (i) state recommendation of use in veterinary practice, (ii) after establishing their real use on each farm and (iii) use in medicine important for humans (penicillin, oxacillin, vancomycin). The results show a resistance of $S$. aureus isolates to a variety of antibiotics (vancomycin, tetracycline, lincomycin), and most for $\beta$-lactams (penicillin and oxacillin). Similar to studies of other authors from different regions of the world, the highest rate of resistance was detected for $\beta$-lactam antibiotics. The resistance to other tested agents was less common, which is also in agreement with the general trend observed worldwide ( $\mathrm{Li}$ et al., 2009; Abebe et al., 2016; Kirmusaoglu, 2017).

In the last few years, there has been a growing interest in multiresistance (resistant to other antibiotics as well as $\beta$-lactams) of $S$. aureus (Brennan et al., 2016; Ganai et al., 2016; Gopal et al., 2017). It has been found that multiresistance of tested $S$. aureus isolates was to between 3 to 5 antimicrobial agents. Twenty isolates (32.3\%) that were resistant to penicillin and oxacillin were also resistant to vancomycin, twelve isolates $(19.4 \%)$ were resistant to 5 antibiotics $\left(\mathrm{P}^{10}, \mathrm{OX}^{1}, \mathrm{VA}^{5}, \mathrm{~L}^{10}, \mathrm{TE}^{30}\right)$ and 3 isolates (4.8\%) were resistant to another 5 antibiotics $\left(\mathrm{P}^{10}, \mathrm{OX}^{1}\right.$, $\mathrm{VA}^{5}, \mathrm{CIP}^{10}, \mathrm{TE}^{30}$. We associate these results with the level of use of antimicrobial agents on each farm.

According to the scientific literature, MRSA is primarily mediated by the mecA gene carried on a mobile genetic element (MGE), the staphylococcal cassette chromosome mec (SCCmec) (Zhang et al., 2005). Several scientific studies conducted in several countries have shown the wide distribution of mecA gene in the world (Pu et al., 2014; Ganai et al., 2016). Our results show that 10 (66.7\%) from 15 isolates of $S$. aureus yielded a mecA product.

\section{Conclusion}

The information obtained from this study is useful for understanding the prevalence of $S$. aureus and its antibiotic sensitivity in dairy farms and can be useful for local and national monitoring or for designning specific control programs of methicillin-resistant and multiresistance isolates present in the food chain of milk production. Also, study of antibiotic resistance among $S$. aureus isolates on each farm is very important, especially for the successful treatment of staphylococcal infections of animals. The presence of isolates resistant to antibiotics, including MRSA, in the raw milk of cows and on dairy farms can be a potential risk in the food chain. The improving of hygienic conditions on dairy farms may reduce the high level of $S$. aureus in environments of farms and in raw milk.

\section{References}

Abebe, R., Hatiya, H., Abera, M., Megersa, B., \& Asmare, K. (2016). Bovine mastitis: Prevalence, risk factors and isolation of Staphylococcus aureus in dairy herds at Hawassa milk shed. South Ethiopia. BMC Veterinary Research, 12, 270-279.

Al-Ashmawy, M. A., Sallam, K. I., Abd-Elghany, S. M., Elhadidy, M., \& Tamura, T. (2016). Prevalence, molecular characterization, and antimicrobial susceptibility of methicillin-resistant Staphylococcus aureus isolated from milk and dairy products. Foodborne Pathogens and Disease, 13(3), 156-162.

Ateba, C. N., Mbewe, M., Moneoang, M. S., \& Bezuidenhout, C. C. (2010). Antibiotic-resistant Staphylococcus aureus isolated from milk in the Mafikeng
Area, North West province, South Africa. South African Joumal of Science, 106(11-12), 1-6.

Bardiau, M., Yamazaki, K., Duprez, J. N., Taminiau, B., Mainil, J. G., \& Ote, I. (2013). Genotypic and phenotypic characterization of methicillin resistant Staphylococcus aureus (MRSA) isolated from milk of bovine mastitis. Letters in Applied Microbiology, 57(3), 181-186.

Basanisi, M. G., La Bella, G., Nobili, G., Franconieri, I., \& La Salandra, G. (2017). Genotyping of methicillin-resistant Staphylococcus aureus (MRSA) isolated from milk and dairy products in South Italy. Food Microbiology, 62, 141-146.

Bhunia, A. K. (2008). Foodborne microbial pathogens: Mechanisms and pathogenesis. Springer Science + Business Media, NY, USA.

Brennan, G. I., Abbott, Y., Burn, A., Leonard, F., McManus, B. A., O’Connell, B., Coleman, D. C., \& Shore, A. C. (2016). The emergence and spread of multiple livestock-associated clonal complex 398 methicillin-resistant and methicillin-susceptible Staphylococcus aureus strains among animals and humans in the Republic of Ireland, 2010-2014. PLoS One, 11, 1-11.

Carfora, V., Caprioli, A., Marri, N., Sagrafoli, D., Boselli, C., Giacinti, G., Sorbara, L., Dottarelli, S., Battisti, A., \& Amatiste, S. (2015). Enterotoxin genes, enterotoxin production, and methicillin resistance in Staphylococcus aureus isolated from milk and dairy products in Central Italy. International Dairy Journal, 42, 12-15.

Deurenberg, R. H., Vink, C., Kalenic, S., Friderich, A. W., Bruggeman, C. A., \& Stobberingh, E. E. (2007). The molecular evolution of methicillin-resistant Staphylococcus aureus. Clinical Microbiology and Infection, 13, 222-235.

Doulgeraki, A. I., Di Ciccio, P., Ianieri, A., \& Nychas, G. J. E. (2017). Methicillinresistant food-related Staphylococcus aureus: A review of current knowledge and biofilm formation for future studies and applications. Research in Microbiology, 168(1), 1-15.

Febler, A., Scott, C., Kadlec, K., Ehricht, R., Monecke, S., \& Schwarz, S. (2010). Characterization of methicillin-resistant Staphylococcus aureus ST-398 from cases of bovine mastitis. Joumal of Antimicrobial Chemotherapy, 65(4), 619-625.

Ganai, A. W., Kotwal, S. K., Wani, N., Malik, M. A., Jeelani, R., Kour, S., \& Zargar, R. (2016). Detection of mecA gene of methicillin resistant Staphylococcus aureus by PCR assay from raw milk. Indian Journal of Animal Sciences, 86(5), 508-511.

Gopal, S., \& Divya, K. C. (2017). Can methicillin-resistant Staphylococcus aureus prevalence from dairy cows in India act as potential risk for communityassociated infections?: A review. Veterinary World, 10(3), 311-318.

Hamid, S., Bhat, M. A., Mir, I. A., Taku, A., Badroo, G. A., Nazki, S., \& Malik, A. (2017). Phenotypic and genotypic characterization of methicillin-resistant Staphylococcus aureus from bovine mastitis. Veterinary World, 10(3), 363-367.

İkiz, S., Basaran, B., Bingol, E. B., Çetin, Ö., Kasikci, G., Özgur, N. Y., Ucmak, M., Yilmaz, Ö., Gunduz, M. C., \& Sabuncu, A. (2013). Presence and antibiotic susceptibility patterns of contagious mastitis agents (Staphylococcus aureus and Streptococcus agalactiae) isolated from milks of dairy cows with subclinical mastitis. Turkish Journal of Veterinary and Animal Sciences, 37, 569-574.

Jihasz-Kaszanytzky, E., Janosi, S., Somogyi, P., Dan, A., Van Der Graaf-Van Bloois, L., Van Duijkeren, E., \& Wangenaar, J. A. (2007). MRSA transmission between cows and humans. Emerging Infectious Diseases,13, 630-632.

Keefe, G. (2012). Update on control of Staphylococcus aureus and Streptococcus agalactiae for management of mastitis. Veterinary Clinics of North America: Food Animal Practice, 28, 203-216.

Kirmusaoglu, S. (2017). MRSA and MSSA: The mechanism of methicillin resistance and the influence of methicillin resistance on biofilm phenotype of Staphylococcus aureus. In: The rise of virulence and antibiotic resistance in Staphylococcus aureus. InTech.

Kukhtyn, M. D., Berhilevych, O. M., Kravcheniuk, K., Shynkaruk, O., Horyuk, Y. V., \& Semaniuk, N. (2017). Formation of biofilms on dairy equipment and the influence of disinfectants on them. Eastern-European Journal of Eenterprise Technologies, 89, 26-33.

Kukhtyn, M. D., Horyuk, Y. V., Horyuk, V. V., Yaroshenko, T. Y., Vichko, O. I., \& Pokotylo, O. S. (2017). Biotype characterization of Staphylococcus aureus from milk and dairy products of private production in the western regions of Ukraine. Regulatory Mechanisms in Biosystems, 8(3), 384-388.

Li, J., Zhou, H., Yuan, L., He, T., \& Hu, S. (2009). Prevalence, genetic diversity, and antimicrobial susceptibility profiles of Staphylococcus aureus isolated from bovine mastitis in Zhejiang Province, China. Journal of Zheijang University SCIENCE B (Biomedicine \& Biotechnology), 10(10), 753-760.

Mehli, L., Hoel, S., Thomassen, G. M. B., Jakobsen, A. N., \& Karlsen, H. (2017). The prevalence, genetic diversity and antibiotic resistance of Staphylococcus aureus in milk, whey, and cheese from artisan farm dairies. International Dairy Journal, 65, 20-27.

Normanno, G., Salandra, G. L., Dambrosio, A., Quaglia, N. C., Corrente, M., Parisi, A., Santagada, G., Firinu, A., Crisetti, E., \& Celano, G. V. (2007). Occurrence, characterization and antimicrobial resistance of enterotoxigenic Stap- 
hylococcus aureus isolated from meat and dairy products. International Journal of Food Microbiology, 115(3), 290-296.

Performance standards for antimicrobial disk susceptibility tests (2012). Approved Standard, CLSI, USA.

Pu, W., Su, Y., Li, J., Li, C., Yang, Z., Deng, H., \& Ni, C. (2014). High incidence of oxacillin-susceptible mecA-positive Staphylococcus aureus (OS-MRSA) associated with bovine mastitis in China. PLoS One, 9(2), 88-134.

Rahim, A., Rachman, A., Suhaili, Z., \& Desa, M. N. (2017). The evolution and dissemination of methicillin resistance determinant in Staphylococcus aureus. In: The rise of virulence and antibiotic resistance in Staphylococcus aureus. InTech.

Sergelidis, D., \& Angelidis, A. S. (2017). Methicillin resistant Staphylococcus aureus (MRSA): A controversial food borne pathogen. Letters in Applied Microbiology, 64(6), 409-418.

Szweda, P., Schielmann, M., Frankowska, A., Kot, B., \& Zalewska, M. (2014). Antibiotic resistance in Staphylococcus aureus strains isolated from cows with mastitis in Eastern Poland and analysis of susceptibility of resistant strains to alternative nonantibiotic agents: Lysostaphin, nisin and polymyxin B. Journal of Veterinary Medical Science, 76(3), 355-362.

Thaker, H. C., Brahmbhatt, M. N., Nayak, J. B., \& Thaker, H. C. (2013). Isolation and identification of Staphylococcus aureus from milk and milk products and their drug resistance patterns in Anand, Gujarat. Veterinary World, 6(1), 10-13.

Wang, X., Li, G., Xia, X., Yang, B., Xi, M., \& Meng, J. (2014). Antimicrobial susceptibility and molecular typing of methicillin-resistant Staphylococcus aureus in retail foods in Shaanxi, China. Foodborne Pathogens and Disease, 11(4), 281-286.

Zhang, K., \& McClure, J.-A. (2005). Novel multiplex PCR assay for characterization and concomitant subtyping of staphylococcal cassette chromosome mec Types I to V in methicillin-resistant Staphylococcus aureus. Journal of Clinical Microbiology, 43(10), 5026-5033. 